TERRA. Revista de Desarrollo Local

e-ISSN: 2386-9968

Número 8 (2021), 733-738

DOI 10.7203/terra.8.20588

IIDL - Instituto Interuniversitario de Desarrollo Local

\title{
Reseña. Espacios protegidos y otros entes imaginarios
}

\author{
Miguel Gómez Ruíz \\ Graduado en Geografía y Medio Ambiente (Universidad de Valencia, España) \\ migoruiz@alumni.uv.es
}

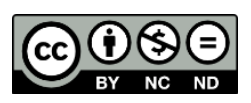

Esta obra se distribuye con la licencia Creative Commons

Reconocimiento-NoComercial-SinObraDerivada 4.0 Internacional 


\section{SECCIÓN RESEÑAS}

\section{Reseña. Espacios protegidos y otros entes imaginarios}

Resumen: La obra aquí reseñada se centra en la crítica hacia la visión ambiental que todavía impera en gran parte de la sociedad y también en el ámbito gubernamental y administrativo, basada en planteamientos antiguos, parciales y prejuiciosos. Al mismo tiempo, se reflexiona acerca del origen de esta problemática, mientras se abordan posibles vías de actuación futuras, que resulten más efectivas y que relacionen de una forma más coherente las actividades de ordenación territorial con la protección del entorno. Se concluye reconociendo las limitaciones jurídicas y económicas que actúan como barreras del progreso ambiental, así como la falta de una plasmación real de las medidas recomendadas.

Palabras clave: áreas protegidas, Red Natura 2000, naturaleza, medioambiente, infraestructura verde.

Recibido: 02 de marzo de 2021

Devuelto para revisión: -

Aceptado: 03 de marzo de 2021

Referencia / Citation:

Gómez, M. (2021). Reseña. Espacios protegidos y otros entes imaginarios. TERRA. Revista de Desarrollo Local, (8), 733-738. DOI 10.7203/terra.8.20588 


\section{Juan Ors Martínez \\ ESPACIOS PROTEGIDOS Y OTROS ENTES IMAGINARIOS}

Madrid (España). Catarata, 2020, 192 páginas

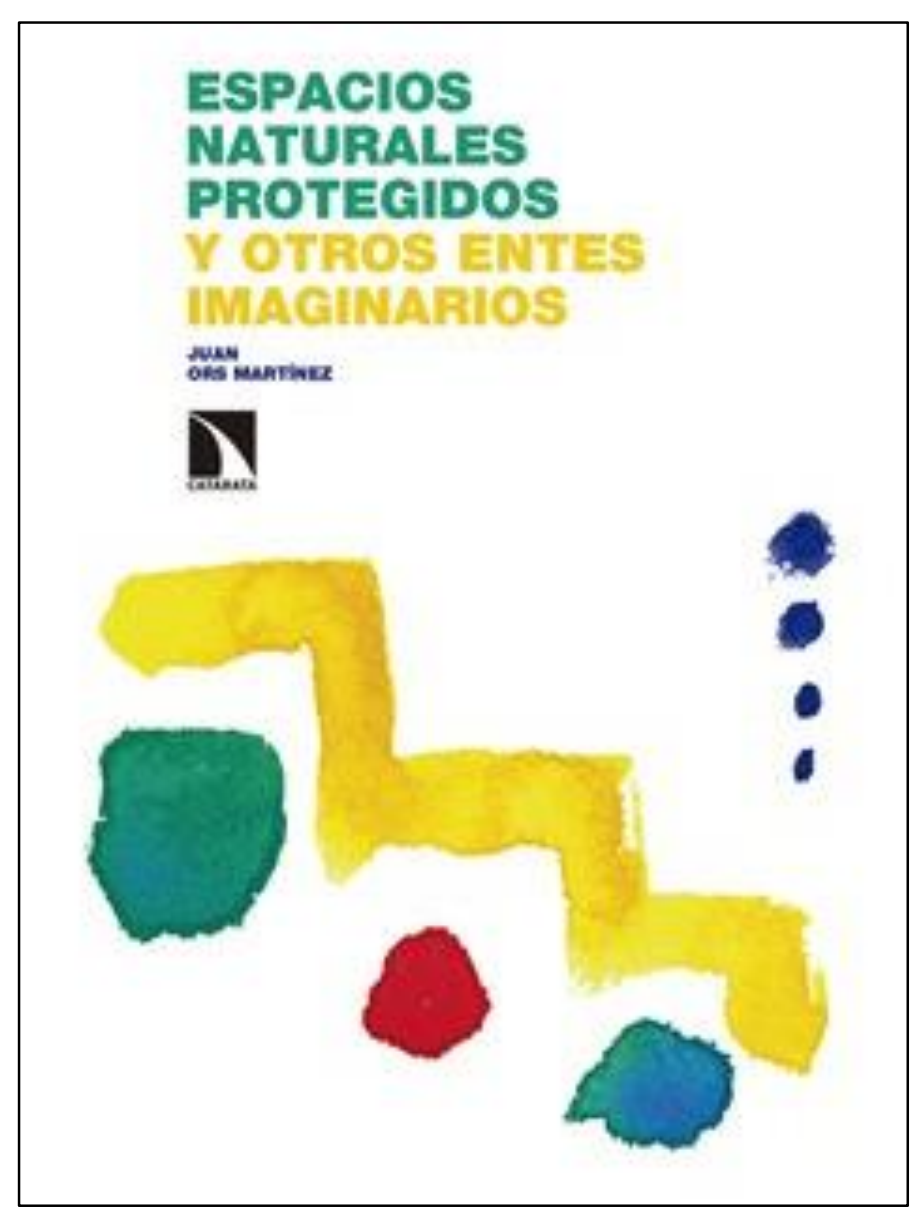

Espacios Protegidos y otros entes imaginarios es el nombre del libro redactado por Joaquín Ors Martínez, biólogo y especialista en materia medioambiental, que desde hace más de 30 años comenzó una fructífera trayectoria profesional en materia de protección ambiental y ordenación del territorio.

Publicado en el año 2020, el discurso del autor se centra en la crítica hacia la visión ambiental que todavía impera en gran parte de la sociedad y también en el ámbito gubernamental y administrativo, basada en planteamientos antiguos, parciales y prejuiciosos. Al mismo tiempo, se reflexiona acerca del origen de esta problemática, mientras se abordan posibles vías de actuación futuras, que resulten más efectivas y que relacionen de una forma más coherente las actividades de ordenación territorial con la protección del entorno.

El hilo conductor de toda la trama planteada, especialmente en la primera mitad, es el recorrido histórico realizado en el que se muestra cómo evoluciona la relación entre Naturaleza y Sociedad a lo largo del tiempo, caracterizándose por una ininterrumpida influencia del ser humano en el medio ya antes del Neolítico, desde que nuestros antepasados fueron capaces de domesticar el fuego.

En este intervalo de tiempo de cientos de miles de años, los cambios ejercidos por el hombre han ido alcanzando una envergadura cada vez mayor, intercalándose los periodos en los que el hombre lograba imponerse a la Naturaleza y viceversa (se citan varios ejemplos en los que cambios ambientales son los responsables de la caída y desaparición de numerosas civilizaciones antiguas).

El autor también utiliza este recorrido histórico para cuestionar algunas visiones edulcoradas y ciertamente irreales, que parte de la sociedad acomodada de hoy en día sigue teniendo respecto al medio ambiente, creyendo fervientemente que el trato hacia éste fue mucho mejor en un pasado no muy lejano. El mundo rural de nuestros abuelos es tomado como modelo, sin tener en cuenta las grandes penurias a las que se tuvieron que enfrentar sus habitantes. El autor asegura que éste es uno de los motivos por los que no 
se avanza con la rapidez necesaria hacia un planteamiento más adecuado en materia ambiental, hacia alternativas que sean mejores que el idealizado mundo rural de finales del siglo XIX y principios del siglo XX.

Otro de los motivos que se anuncian como clave de la problemática ambiental, es el excesivo peso que se sigue otorgando a la figura de Área Protegida, considerada como el 'Santo Grial' de la jurisprudencia ambiental y criticándose el hecho de que todavía y en muchas ocasiones, sea la vía contemplada para proteger, conservar y gestionar únicamente los espacios más valiosos del territorio. Además, el autor defiende que el panorama en el que se creó esta figura (finales del siglo XIX) es muy diferente al que tenemos en la actualidad. En aquel momento, las áreas protegidas se crearon para evitar que el avance imparable de las sociedades por nuevos espacios, destruyese los rincones más bellos del territorio y, como bien apunta el autor, se produjo una musealización de la Naturaleza. El contexto actual es bien diferente, siendo evidente que todos los paisajes, excepto aquellos ubicados en los lugares más recónditos y aislados, han sido modificados por el hombre, por lo que no hay que aislar ciertos fragmentos de naturaleza totalmente de éste, sino aprender la forma adecuada para que las actividades humanas se desarrollen de forma armoniosa en el territorio.

En resumidas cuentas, en el panorama actual se entremezcla una nostalgia hacia épocas pasadas consideradas mejores en lo referente a la temática medioambiental, con una excesiva importancia de figuras de protección que aplican medidas muy restrictivas para garantizar la viabilidad de los ecosistemas, pero en lugares muy concretos del territorio, mientras la gestión territorial mayoritaria permanece sin cambios. De hecho, el autor argumenta lo siguiente: "solo desde la ambientalización de las políticas con incidencia territorial se podrá frenar la destrucción de los ecosistemas y la pérdida de biodiversidad [...] aunque las áreas protegidas juegan un papel fundamental frente a la destrucción de la arquitectura ecosistémica de ciertos fragmentos territoriales, estas no suelen ser suficientes para proteger los procesos medioambientales y la biodiversidad a medio y largo plazo".

Ante esto, el autor defiende una aproximación entre las políticas de conservación de la Naturaleza y las políticas de ordenación territorial, al mismo tiempo que resalta la importancia de definir unos objetivos coherentes y desvinculados de cualquier influencia política, para así evitar que los vaivenes en esta disciplina perjudiquen la evolución positiva del medio.

Además, se nos hace dudar acerca de la utilidad real y actual de ciertos instrumentos jurídicos en los que se basa la gestión de un Área Protegida como puede ser el Plan de Ordenación de Recursos Naturales (PORN), defendiendo que ciertas herramientas, como las actuaciones ambientales estratégicas o las evaluaciones de impacto ambiental, ya contemplan en sus respectivas normativas todo lo necesario para evitar el daño medioambiental de esas zonas protegidas. Insiste en el exceso de normas jurídicas destinadas a la gestión de esta disciplina y a cómo sus numerosas interrelaciones entorpecen más que otra cosa en la toma de decisiones.

A modo de síntesis y a pesar de las críticas hacia su todavía excesivo peso, la obra zanja su planteamiento destacando que las Áreas Protegidas sí deben perdurar en el tiempo, pero para proteger las zonas más valiosas y vulnerables, mientras en el resto del territorio se han de plasmar y desarrollar las medidas contempladas en otras figuras de protección más flexibles y amoldables a las actividades socio-económicas del territorio. El autor visualiza a la Red Natura 2000 y a la Infraestructura Verde como las líneas de actuación potenciales para lograr este cometido. La primera figura incluye en su catálogo de zonas 
protegidas territorios aparentemente mediocres o carentes de recursos valiosos y estéticos, pero que juegan un papel importante en el entramado ecológico de la región. La segunda incluye toda una gama de espacios naturales y seminaturales en los que se combinan elementos muy diversos entre sí, algunos de ellos hasta ahora carentes de importancia (bosques, humedales, cultivos, acequias, parques periurbanos...) pero que juntos logran maximizar la correcta dinámica ambiental de la zona.

Asimismo, se defiende que las zonas rurales tradicionalmente empobrecidas y dependientes de las urbes, se emancipen de las subvenciones proporcionadas por las administraciones públicas, para procurar su supervivencia en un mundo en el que estos territorios son cada vez son menos necesarios. Esto podría lograrse a través de un sistema de Pagos por Servicios Ambientales (PSE) bien estructurado, en el que las diferentes empresas decidieran compensar económicamente a los propietarios y residentes de las zonas rurales, por utilizar sus recursos y desarrollar sus actividades.

Se concluye reconociendo las limitaciones jurídicas y económicas que actúan como barreras del progreso ambiental, así como la falta de una plasmación real de las medidas recomendadas.

En nuestra opinión, se trata de una obra instructiva y esclarecedora, donde se descubren curiosidades y puntos de vista desconocidos que nos llevan a reflexionar sobre el la conceptualización de los espacios protegidos. Además, nos permite entender mejor cómo funciona la gestión del medio ambiente, procedimiento que continúa siendo algo abstracto y difícil de acotar al menos para el público en general, pero que gracias a lo aquí expuesto, se consigue entender mejor.

A partir de lo expuesto, consideramos que una de las herramientas clave para lograr un medio ambiente cada vez mejor gestionado es la educación de la ciudadanía. Se debe seguir concienciando desde bien pequeño a las próximas generaciones sobre la importancia que posee la Naturaleza, para que cuando se conviertan en adultos y algunos de ellos adquieran puestos de dirección y liderazgo, sean capaces de anteponer el bien común, en forma de prácticas respetuosas con el medio y compatibles con el desarrollo sostenible, a la consecución de objetivos particulares mediante prácticas poco honorables. Claramente está en manos de todos avanzar en esta línea y encabezar el ansiado cambio de paradigma medioambiental. No obstante, gracias a la educación ambiental generalizada y detallada, los ciudadanos podremos implementar también numerosas pautas sostenibles (comercio local o de proximidad, productos ecológicos, disminución en el consumo de productos animales, reciclaje, utilización de transporte público, inscripción en asociaciones ambientales...) cuyo efecto individual sería mucho más modesto, pero considerable si fueran miles sino millones las personas que las ponen en práctica.

Para finalizar nos gustaría respaldar la opinión del autor acerca de la necesidad de otorgar una importancia cada vez mayor a conceptos como la Infraestructura Verde o la Red Natura 2000, pues consideramos que poseen un gran potencial no solo para asegurar la viabilidad ecosistémica de las áreas protegidas, al actuar como "conectores ecológicos", sino también para cambiar la mente de las personas que continúan pensando que los paisajes más bellos, estéticamente hablando, son aquellos en los que hay que centrar la protección. Todo está interrelacionado en materia ambiental y si proteges un porcentaje ínfimo del territorio mientras sangras y destrozas al resto, es que no hemos entendido la dinámica natural. Recalco de nuevo con esta última afirmación la necesidad de una buena educación ambiental desde edades tempranas. 
Miguel Gómez Ruíz.

Graduado en Geografía y Medio Ambiente. Universitat de València 